\title{
Use of Confocal Raman Microscopy to Characterise Ethyl Cyanoacrylate Adhesive Depth Curing
}

\author{
Kevin Raheem \\ Technological University Dublin \\ John Cassidy \\ Technological University Dublin, john.cassidy@tudublin.ie \\ Tony Betts \\ Technological University Dublin, anthony.betts@tudublin.ie
}

See next page for additional authors

Follow this and additional works at: https://arrow.tudublin.ie/aegart

Part of the Chemistry Commons

\section{Recommended Citation}

Raheem, K., Cassidy, J., Betts, A., \& Ryan, B. (2020). Use of confocal Raman microscopy to characterise ethyl cyanoacrylate adhesive depth curing. Physical Chemistry Chemical Physics,22, 23899-23907. doi:10.1039/D0CP04053C

This Article is brought to you for free and open access by the Applied Electrochemistry Group at ARROW@TU Dublin. It has been accepted for inclusion in Articles by an authorized administrator of ARROW@TU Dublin. For more information, please contact arrow.admin@tudublin.ie, aisling.coyne@tudublin.ie, gerard.connolly@tudublin.ie.

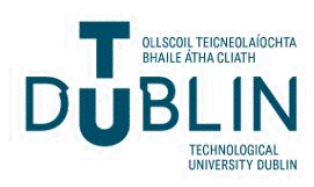




\section{Authors}

Kevin Raheem, John Cassidy, Tony Betts, and Bernard Ryan

This article is available at ARROW@TU Dublin: https://arrow.tudublin.ie/aegart/12 


\title{
Use of Confocal Raman Microscopy to Characterise Ethyl Cyanoacrylate Adhesive Depth Curing
}

\author{
Authors: Kevin Raheem, ${ }^{* a, b}$ John Cassidy ${ }^{\mathrm{a}, \mathrm{b}}$ Anthony Betts ${ }^{\mathrm{a}, \mathrm{b}}$ and Bernard Ryan ${ }^{\mathrm{c}}$
}

\begin{abstract}
In-situ spatial temporal measurement of monomer conversion during adhesive bondline curing remains a challenging area. The aim of this work was to demonstrate the effectiveness of using Confocal Raman Microscopy in a specially configured experimental set-up, as a versatile tool for measuring monomer concentration changes as a function of both time and adhesive bond depth during ethyl cyanoacrylate polymerisation. This also allowed monitoring of the extent of polymerisation at the adhesive substrate interface independently of the bulk bondline polymerisation region. Key kinetic parameters such as Inhibition time $t_{\text {lag }}$, rate of reaction $R_{\max }$ and extent of reaction $\left[\alpha_{t}\right]_{\max }$ were obtained by fitting the experimental data to sigmoidal growth curves using simple piecewise regression models. A systematic characterisation of a polymerisation reaction was conducted using different sample substrate types (copper alloy (red brass), aluminium, aluminium alloy, stainless steel and borosilicate glass) and at various reaction temperatures.

Reaction rates were found to decrease further away from the substrate interface in the bulk volume region. The fastest kinetics occurred in the vicinity of nucleophilic hydroxyl rich surfaces such as at the copper alloy (red brass). In addition to substrate surface chemistry, surface roughness was also a factor, with the highest reaction rates occurring with a grit blasted (roughened) aluminium alloy (2024 T3) surface. An approximately linear dependence of the $\ln R_{\max }$ vs $1 / \mathrm{T}$ (Arrhenius) plot was recorded within the temperature range of 291-328 K. A better fit was obtained however through the use of two separate linear slopes, possibly indicative of a change of polymerisation reaction mechanism taking place at elevated temperatures with two distinct activation energies. Further work conducted using a larger number of temperatures would be useful to verify this finding. This work confirmed that differences in the rates of interfacial and bulk polymerisation processes could be readily measured in-situ using Confocal Raman Microscopy which is a powerful technique for investigating such surface-confined and bulk polymerisation reactions.
\end{abstract}

\footnotetext{
a. Applied Electrochemistry Group, Technological University Dublin, Camden Row, Dublin, Ireland.

b. Chemical and Pharmaceutical Sciences, Technological University Dublin, City Campus, Kevin Street, Dublin, D08NF72, Ireland.

c. Ireland, Henkel, Tallaght Business Park, Whitestown Industrial Estate, Dublin 24, Ireland
} 


\section{Introduction}

Cyanoacrylates (CAs) are one of many types of fast acting synthetic adhesives also known as "Super Glue" or "instant adhesives" in the consumer market. Rapid cure speed and high bond strengths are typical key characteristics of 2-cyanoacrylate based commercial adhesives. CA's are known to undergo anionic and zwitterion polymerisation in which high cure speeds are brought about by the presence of nucleophilic species such as hydroxide ions that are found on surfaces or by Lewis bases such as amines or alcohols. Various studies have reported the polymerisation mechanisms of Ethyl Cyanoacrylate ECA ${ }^{1-3}$.

The heterogeneous nature of the surface initiated curing leads to adhesive joints in which the performance and mechanical strengths greatly depend on the chemical and physical nature of the bonding surfaces and the gap between both surfaces. When bonding two surfaces it is desirable to have virtually direct contact between them. A so-called "zero gap" is typically $10 \mu \mathrm{m}$. However due to uneven surface topographies bond gaps of $50-500 \mu \mathrm{m}$ can be encountered. Effective cure through larger bond gaps or Cure Through Volume (CTV), whilst maintaining mechanical strength and cure speed, has proven to be challenging and has limited the usefulness of CA adhesives. Although little is known about the mechanism of bondline curing due to the lack of in-situ methods for studying bondline reactions, initial poor bond strength or bond failure is most often attributed to insufficient monomer polymerisation. A bondline refers to the adhesive interlayer between two structurally bonded surfaces.

Significant progress towards adhesive performance improvement can be realized through the development of a suitable spatial temporal method capable of studying localised curing behaviour or conversion at different spatial locations within the bondline. Over recent years, several optical spectroscopy techniques such as FTIR and Raman spectroscopy have been widely applied as powerful non- destructive methods to follow dynamic polymerisation reactions ${ }^{4-6}$. This paper presents Confocal Raman Microscopy (CRM) as a simple, efficient and accurate method for this type of investigation. The biggest benefit of Raman spectroscopy with regards to this research is the coupling of a confocal microscope as a sampling accessory. Microscope objectives are capable of providing spatial selectivity within different regions of the bondline. By utilising the microscope optics, Raman scattered light from outside the focal plane can be blocked allowing for accurate depth profile analysis. Optical immersion objectives limit sample interfacial refraction effects and Raman signal can be generated with a depth resolution $\sim 2.5 \mu \mathrm{m}$ in optimised conditions $\mathrm{s}^{7,8}$.

Many applications have demonstrated that CRM is particularly suited to examine the depth profile of a wide range of materials such as pigments, polymer films and coatings ${ }^{9-11}$. For example, Schrof et al also conducted depth profile studies to investigate the inhomogeneous distribution of pigments in UV cured coatings ${ }^{12,13}$. The distribution of small molecules in dry latex films was investigated by $\mathrm{F}$. Belarouia et $\mathrm{al}^{14}$. Courtecuisse et al demonstrated the effect of oxygen inhibition in an acrylate photopolymerization system ${ }^{15}$. Smith-Palmer et al used CRM to follow the initiation of biofouling by a marine bacterium in a flow cell ${ }^{16}$. Edwards et al have employed Raman spectroscopy to study curing of a cyanoacrylate system for the forensic enhancement of latent fingerprints ${ }^{17}{ }^{18}$. Recently Nedvedova et al analysed various polymerised N-butyl-2-cyanoacrylate-Lipiodol mixtures by Raman spectra mapping of the CA polymer $\mathrm{x}$-y direction ${ }^{4}$, however cyanoacylate compositional changes along the z-axis was not explored. When considering the range of applications that are used in industry for the determination of cyanoacrylate chemical heterogeneity ${ }^{19,5}$, it is perhaps surprising that little work has gone into utilising Confocal Raman spectroscopy to probe interfacial and diffusional aspects of bondline polymerisations and the study of spatially resolved polymerisation/curing rates. To the best of the author's knowledge Confocal Raman Microscopy has 
never been used to examine the interfacial curing of cyanoacrylate polymers. A novel characterisation methodology which aims to develop an expression for the temporal and spatial change of monomer concentration is discussed here. Such a system may provide a holistic picture of the surface events which could be key to establishing quantitative relationships to guide formulation strategies.

\section{Materials and Methods}

\section{A. Confocal Raman Microscopy}

Raman spectra were obtained using a Horiba Jobin Yvon LabRAM HR 800 Raman Microscope with a $532 \mathrm{~nm}$ solid state diode laser excitation source and an adjusted $0.5 \mathrm{~mW}$ laser power at the sample. The effect of the refractive index mismatch between the sample and the medium surrounding the objective was reduced by using an Olympus-LUMPlanFL-100x water immersion objective. The primary advantage of this water immersion objective is the long working distance compared to oil immersion objectives which typically provide better refractive index matching to ECA but have considerably lower working distances ${ }^{20}$.

A depth profile was achieved by focusing the Raman microscope optics at multiple points within the monomer sample. Raman spectra were collected at each point as a motorised stage moved the focal position in $\mu \mathrm{m}$ steps in the $Z$ direction as shown in Figure 1 . In this setup, the z-axis is defined as the distance between bonding surfaces. The three regions shown in Figure 1 were used to characterise the cure through volume (CTV) performance of different adhesive formulations. Region A represents $z \approx 0$ or effectively the reactive interface at which polymerisation begins. This was typically monitored from the surface closest to the cover slip, but it could also be measured at the bottom surface when studying substrate effects. The progress of the surface initiated cure deeper into the volume was monitored by recording the local monomer concentration at Region B and Region C. The latter refers to the location in the centre of the bond assembly. All measurements were conducted using a diffraction grating of $600 \mathrm{~mm}$ to ensure high spectral resolution. A confocal pinhole aperture of $50 \mu \mathrm{m}$ was used to ensure depth resolution. Previous investigations have shown that the spatial distribution of the illuminated volume depends both on the pinhole size and the penetration depth $^{8,7}$. Raman Spectra were obtained using $30 \mathrm{sec}$ exposure times of the Charge-Coupled Device (CCD) detector in the region $1000 \mathrm{~cm}^{-1}-2500 \mathrm{~cm}^{-1}$. In order to record the cure depth profiles for the polymerisation of cyanoacrylate monomers, spectra were collected at 60 s time intervals alternating in a cyclical manner between all three regions of interest. Temperature dependence studies were conducted using a model ECA formulation on an aluminium 2024 substrate due the high thermal conductivity of aluminium. Linkam THMS600 heating and freezing microscope stage was used to control the temperature of the reaction to $0.1^{\circ} \mathrm{C}$ accuracy.

\section{B. Sample preparation}

Freshly formulated Ethyl Cyanoacrylate (ECA) monomers, stabilized with ppm quantities of strong acid and stored at $-20^{\circ} \mathrm{C}$, were used for the experiments. The monomers were supplied by Henkel Ireland $\mathrm{Ltd}$. A range of materials routinely added to Cyanoacrylate monomer to improve properties such as cure accelerators (Crown Ether) were assessed. Unless otherwise specified, a model formulation consisting of strong acid stabilised ECA monomer with $0.02 \% \mathrm{w} / \mathrm{v}$ 18-Crown-6 ( $\geq 99.0 \%$, 
Sigma-Aldrich, Ireland) was used for most investigations carried out in this study. Formulations were stored at $3-4^{\circ} \mathrm{C}$ and kept no longer than 2-3 days. All experiments were carried out at a controlled room temperature of $16-18^{\circ} \mathrm{C}$ and humidity levels ranging from $35-45 \% \mathrm{RH}$. The overall experimental time depended on factors such as the material system, temperature and film thickness and typically varied from minutes to several hours. CRM spectra were collected at various time intervals up to the total cure time using the polymerisation cell as shown in Figure 1. A silicone grease well of $6 \mathrm{~mm}$ diameter was imprinted onto the surface of a borosilicate glass cover slip and was the placed on a level microscope stage. This ensured the sample reaction area was maintained along the $x / y$ axis. $A$ fixed $10 \mu \mathrm{L}$ volume of ECA monomer was allowed to fill the well enclosure and a second Borosilicate glass cover slip was then brought down to contact the adhesive drop, creating a liquid bridge between the two plates. A finely machined plastic spacer controlled the distance between two substrates as shown in Figure 1. A drop of water was placed on the top coverslip and the water immersion objective was lowered and focused at the top adhesive/glass interface prior to analysis. The focal plane was changed using the microscope stage. A customised script was created using Visual Basic that automated the collection of time/spatial dependent parameters of the experimental protocol such as the total acquisition time and motor movement. This permitted accurate and reliable depth profile mapping of the chemical process. This setup also has the added advantage of reducing evaporation of monomer by creating an enclosure for the monomer and protecting the objective lens from a polymerising sample. Triplicate experiments were carried out for each experimental condition. Substrates tested were supplied by Henkel Ireland Ltd which were standard test substrates sourced from Q-Lab and cut to dimensions of $1.5 \times 25 \times 100 \mathrm{~mm}$. These substrates are described in Henkel product Technical Data Sheets (TDS). The bonding surfaces of the different metal substrates were cleaned with isopropyl alcohol and lint free paper prior to use. The surface roughness $R_{a}(\mathrm{~nm})$ of the substrates was evaluated by Henkel. Roughened surfaces were generated by a grit blasting process. An $R_{a}$ of $1550(\mathrm{~nm})$ was recorded on grit blasted surfaces compared to a $200 \mathrm{R}_{\mathrm{a}}$ value for non grit blasted control substrates. Surface roughness was evaluated using a Surfanalyzer $4000^{21}$. The table of substrates and their chemical compositions are shown in Table 1 taken from the supplier's specifications.

Table 1: Substrate composition (\% $\mathrm{w} / \mathrm{w})$ and surface roughness.

\begin{tabular}{|c|c|c|c|c|c|c|}
\hline & $\begin{array}{c}\text { Aluminium } \\
\text { 2024T3 } \\
\text { Bare }\end{array}$ & $\begin{array}{c}\text { Aluminium } \\
\text { (AlClad) }\end{array}$ & $\begin{array}{c}\text { Grit } \\
\text { Blasted } \\
\text { Aluminium } \\
\text { 2024T3 }\end{array}$ & $\begin{array}{c}\text { Borosilicate } \\
\text { Glass }\end{array}$ & $\begin{array}{c}\text { Stainless } \\
\text { Steel (304) }\end{array}$ & $\begin{array}{c}\text { Copper } \\
\text { (Red } \\
\text { Brass) }\end{array}$ \\
\hline Aluminium & $90.7-93.1$ & 99.3 & $90.7-93.1$ & 4.2 & - & - \\
\hline Boron & - & - & - & 8.4 & - & - \\
\hline Carbon & - & - & - & - & 0.08 & - \\
\hline Chromium & 0.1 & - & 0.1 & - & $18-20$ & - \\
\hline Copper & $3.8-4.9$ & 0.10 & $3.8-4.9$ & - & & $84-86$ \\
\hline Iron & 0.5 & - & 0.5 & - & $66.5-71.1$ & 0.05 \\
\hline Manganese & $0.3-0.9$ & 0.05 & $0.3-0.9$ & - & 2 & - \\
\hline Magnesium & $1.2-1.8$ & 0.05 & $1.2-1.8$ & - & -- & - \\
\hline Nickle & - & - & - & - & 8.0010 .50 & - \\
\hline Potassium & - & - & - & 6.9 & - & - \\
\hline Silicon & 0.5 & - & 0.5 & 64.1 & 0.75 & - \\
\hline Sodium & - & - & - & 6.4 & - & - \\
\hline Titanium & 0.15 & 0.03 & 0.15 & 4.0 & - & - \\
\hline Zinc & 0.25 & 0.10 & 0.25 & 5.9 & - & 15 \\
\hline
\end{tabular}




\begin{tabular}{|c|c|c|c|c|c|c|}
\hline $\begin{array}{c}\text { Others } \\
\text { (total) }\end{array}$ & 0.15 & 0.03 & 0.15 & 0.1 & 0.1 & 0.05 \\
\hline & & & & & & \\
\hline $\begin{array}{c}\text { Surface } \\
\text { Roughness } \\
\mathrm{R}_{\mathrm{a}}(\mathrm{nm})\end{array}$ & $<200$ & $<200$ & 1550 & $<200$ & $<200$ & 1300 \\
\hline
\end{tabular}

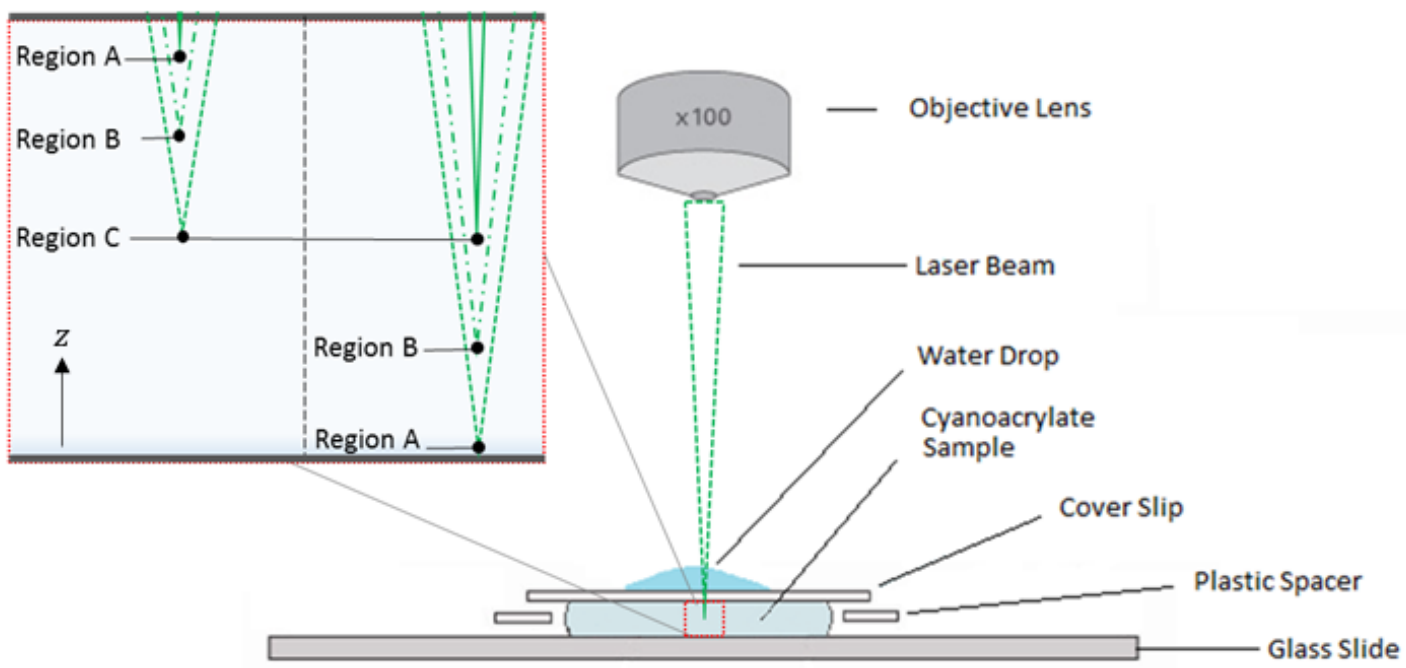

Figure 1: Schematic of Confocal Raman experimental setup used to study adhesive polymerisation. Insert shows various adhesive bond depths that were sampled.

\section{Data Processing}

Raw spectral data obtained was transferred to R studio for data analysis. Pre-processing step such as baseline subtraction for removing background effects from spectra was carried out. Baseline subtraction was carried out by the iterative mean suppression method implemented in the $\mathrm{R}$ package 'baseline' found in the CRAN repository ${ }^{22}$. Spectra were also smoothed to reduce noise using the Savitsky-Golay algorithm ${ }^{23}$. After pre-processing, quantitative analysis was carried out on spectral peaks associated with cyanoacrylate monomer.

A rate plot based on measuring the decreasing peak area of the $\mathrm{C}=\mathrm{C}$ double bond stretch associated with the monomer was developed. Figure 2 shows the Raman spectrum of the ECA monomer, peaks corresponding to the stretch $\mathrm{C}=\mathrm{C}$ at $1621 \mathrm{~cm}^{-1}$ which decreased with time, and the corresponding ester $\mathrm{CH}_{2}$ peak at $1450 \mathrm{~cm}^{-1}$. The ester $\mathrm{CH}_{2}$ peak area was used as an internal standard to normalise spectral data in order to compensate for variable signal intensity due to changes in light scattering or instrumental fluctuations over time. This normalisation approach has been used previously in mid-IR spectroscopic studies ${ }^{5,24}$. Other cyanoacrylates spectral bands can also be distinguished such as $\mathrm{C}=\mathrm{O}$ stretching at $1735 \mathrm{~cm}^{-1}$ and $\mathrm{C} \equiv \mathrm{N} 2340 \mathrm{~cm}^{-1}$ that also decrease in intensity during curing. The intensity decreases can be linked to conversion of the vinyl group that results in a loss of resonance /delocalisation of the carbonyl and nitrile groups and to changes in their inter/ intramolecular hydrogen bonding ${ }^{5,25}$. Equation 1 was used to calculate the extent of reaction at various time 
intervals during a polymerisation. A plot of the extent of reaction $\left[\alpha_{t}\right]$ against time was sigmoidal and used for kinetic measurements that yielded information regarding initiation, propagation and termination processes.

$$
\left[\alpha_{t}\right]=\left(1-\frac{\left([\mathrm{C}=\mathrm{C}] /\left[\mathrm{CH}_{2}\right]\right)_{t}}{\left([\mathrm{C}=\mathrm{C}] /\left[\mathrm{CH}_{2}\right]\right)_{t=0}}\right) \times 100
$$

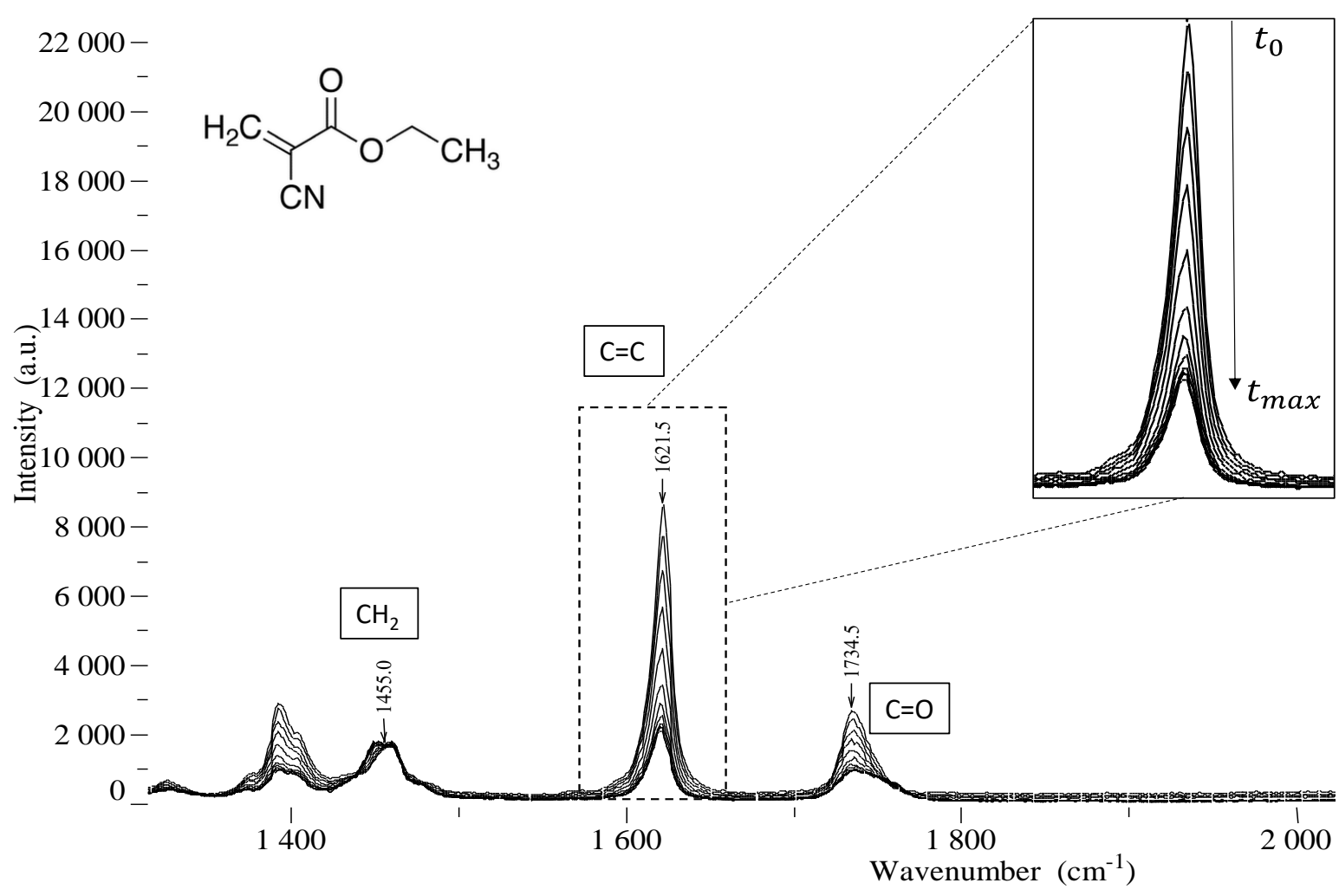

Figure 2: Raman Spectra of the ethyl cyanoacrylate indicating key $\mathrm{C}=\mathrm{C}$ stretch $\left(1621 \mathrm{~cm}^{-1}\right)$ and $\mathrm{CH}_{2}$ stretch $1450 \mathrm{~cm}^{-1}$. The decrease in the $\mathrm{C}=0$ stretch intensity at $1735 \mathrm{~cm}^{-1}$ is also indicated, although the carbonyl group is not thought to participate in the polymerisation. The chemical structure of ethyl cyanoacrylate is shown in the top left hand corner.

\section{Kinetics and Modelling}

A simplified elementary reaction scheme for anionically initiated CA polymerisations is shown below in equations (2)-(5). Where I, M, HA and P are initiator, monomer, acid and propagating polymer respectively ${ }^{26}$. 


$$
\begin{array}{cc}
\mathrm{I}^{-}+\mathrm{M} \stackrel{\mathrm{k}_{\mathrm{i}}}{\rightarrow} \mathrm{P}_{1}^{-} & \text {initiation } \\
\mathrm{P}_{1}^{-}+\mathrm{M} \stackrel{\mathrm{k}_{\mathrm{p}}}{\rightarrow} \mathrm{P}_{\mathrm{m}}^{-} & \text {propagation } \\
\mathrm{P}_{\mathrm{m}}^{-}+\mathrm{M} \stackrel{\mathrm{k}_{\mathrm{p}}}{\rightarrow} \mathrm{P}_{\mathrm{m}+1} & \text { propagation } \\
\mathrm{P}_{\mathrm{m}}{ }^{-}+\mathrm{HA} \stackrel{\mathrm{k}_{\mathrm{t}}}{\rightarrow} \mathrm{P}_{\mathrm{m}} \mathrm{H}+\mathrm{A}^{-} & \text {termination }
\end{array}
$$

A comprehensive theory of slow-initiated-non terminated (SINT) kinetics developed by Pepper et al permitted derivation of composite initiation and propagation rate constants for dilute CA polymerisation using a range of initiators and solvents ${ }^{1,2}$. However SINT kinetics can only be partly applied to bulk ECA polymerisations owing to constraints such the initial constant monomer concentration and changes such as viscosity, dielectric constant and temperature that occur during bulk polymerisation. Furthermore, no model exists for the polymerisation of neat ECA catalysed by heterogeneous substrates.

Different approaches have been proposed to model the vitrification process that occurs at high monomer conversions which results in a diffusion-controlled polymerisation. Smith introduced a modified Gompertz function to describe the sigmoidal change in monomer concentration in photoinduced radical polymerisation of double bonds ${ }^{27}$. Semi empirical functions such as these have been used to model a wide range of growth systems. The Finke-Watzky is another example of a two step phenomenological model used to describe the nucleation and autocatalysis of transition metal nanoclusters ${ }^{28}$. For complex mechanisms, a simple model for fitting the data is preferable. Here a piecewise regression method with no priori model assumptions was used to define key polymerisation parameters. Although a mechanistic modelling approach that yields physical meaning is desirable, the empirical regression approach allows a simpler approximation of the overall system and has been used previously in the analysis of other complex reaction mechanisms ${ }^{29-31}$.

A piecewise cubic spline curve fitting technique was initially employed to model the growth plot shown in Figure 3. Regression analysis using splines is common and the statistical theory behind this regression method is well known and has been comprehensively reviewed elsewhere ${ }^{32}$. Having obtained an optimised fit by minimizing the sum of squares, key kinetic characteristic parameters such as the maximum polymerisation rate $R_{\max }$, and maximum extent of reaction $\left[\alpha_{t}\right]_{\max }$ were calculated as follows. The maximum reaction rate or the maximum velocity was denoted by the term $R_{\max }$ which is obtained from the first derivative $(d \alpha / d t)_{\max }$ of the fitted curve as illustrated in Figure 3. The maximum extent of reaction $\left[\alpha_{t}\right]_{\max }$ corresponding to the monomer concentration at the end of the reaction time was also recorded. Furthermore, piecewise linear regression of the rate curve was carried out using R-Studio Segmented package ${ }^{33}$ that allowed the determination of the inhibition time $t_{\text {lag }}$. This has been shown to be an appropriate diagnostic tool to detect departures from linearity by statistically estimating the breakpoint or the maximum change in slopes ${ }^{34-37}$. Here the inhibition period is defined as the point of maximum acceleration $d^{2} \alpha / d t^{2}$ or the first turning point of the sigmoidal curve. The Inhibition time depends on the overall initiation rate and on the concentration of stabilising acid. The approach, as presented above, captures features of the rate curve and provides simple relationships to describe the polymerisation kinetics. 


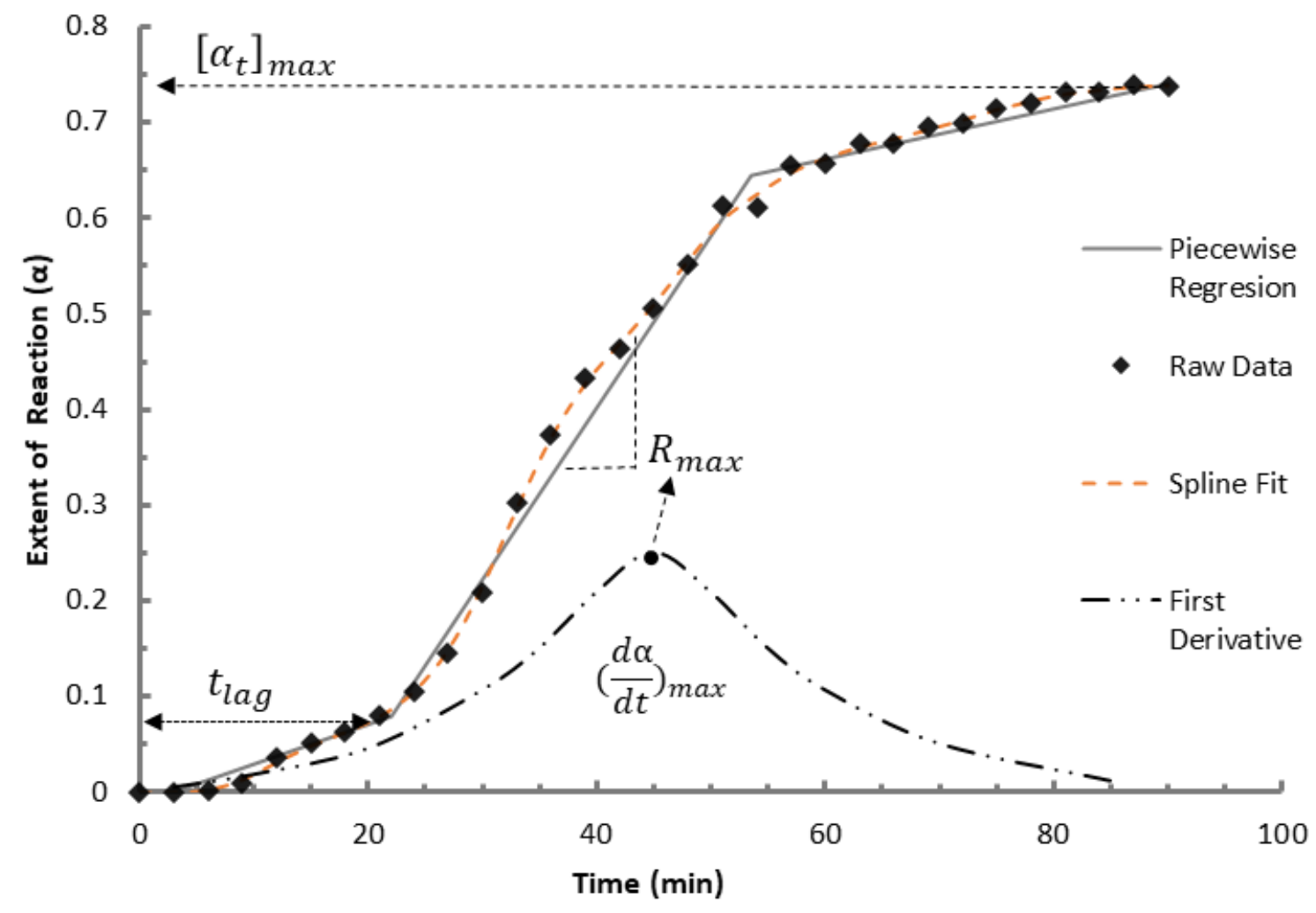

Figure 3: Plot of the extent of polymerisation as a function of time showing the sigmoidal shape of the conversion curve and associated derived parameters: length of lag phase $t_{l a g}$, growth rate $R_{\max }$ and the maximum extent of reaction $\left[\alpha_{t}\right]_{\max }$. The results were obtained at the glass surface $\mathrm{z} \approx 0 \mu \mathrm{m}$ using a $300 \mu \mathrm{m}$ spacer and a model formulation that comprised of strong acid stabilised ECA that contained $0.02 \% 18-$ Crown- 6 ether.

\section{Results and Discussion}

Time evolution of ECA polymerisation as a function of Depth

A time dependent polymerisation reaction of un-stabilised distilled ECA monomer between two glass surfaces separated by a $500 \mu \mathrm{m}$ spacer is shown in Figure 4 . Raman spectra at different positions in the sample were measured up to 90 minutes at room temperature $\left(16^{\circ} \mathrm{C}\right)$. The 
measurements commenced at the Glass/monomer interface, which is notated as region A in Figure 1 , the focal plane was moved $125 \mu \mathrm{m}$ and $250 \mu \mathrm{m}$ away from the glass cover slip surface. This procedure was cycled to yield a time dependent concentration profile through the sample. The key parameters related to the cure profile are noted in Table 2. It is apparent from Figure 4 that there are significant differences in the polymerisation kinetics at the measured spatial position within the bondline. At a given time, chemical changes occurred faster in the vicinity of the surface at $0 \mu \mathrm{m}$ when compared to the centre of the bondline at $250 \mu \mathrm{m}$. The extent of reaction shown highlights the heterogeneous curing behaviour of an ECA monomer on an active surface. A higher maximum extent of reaction $\left[\alpha_{t}\right]_{\max }(z, 0)$ of $95 \%$ was recorded at the glass spacer interface compared to only $78 \%$ recorded at $(z, 250)$ into the bond line. Once the reaction is initiated, the ECA monomer gradually polymerizes into the bulk volume (Cure through Volume), leading to the propagation of reactive species along the $z$ axis. A slight increase in inhibition time with increasing distance away from the surface was found. Raman spectroscopy has been employed to ascertain diffusion coefficients in binary mixtures ${ }^{38}$. However the inter-diffusion of polymeric ECA species into the monomer bulk volume yields variable diffusion coefficients as the composition and viscosity changes with time. The challenge of concentration dependent diffusion requires specialised diffusion based models that will be addressed in a later paper.

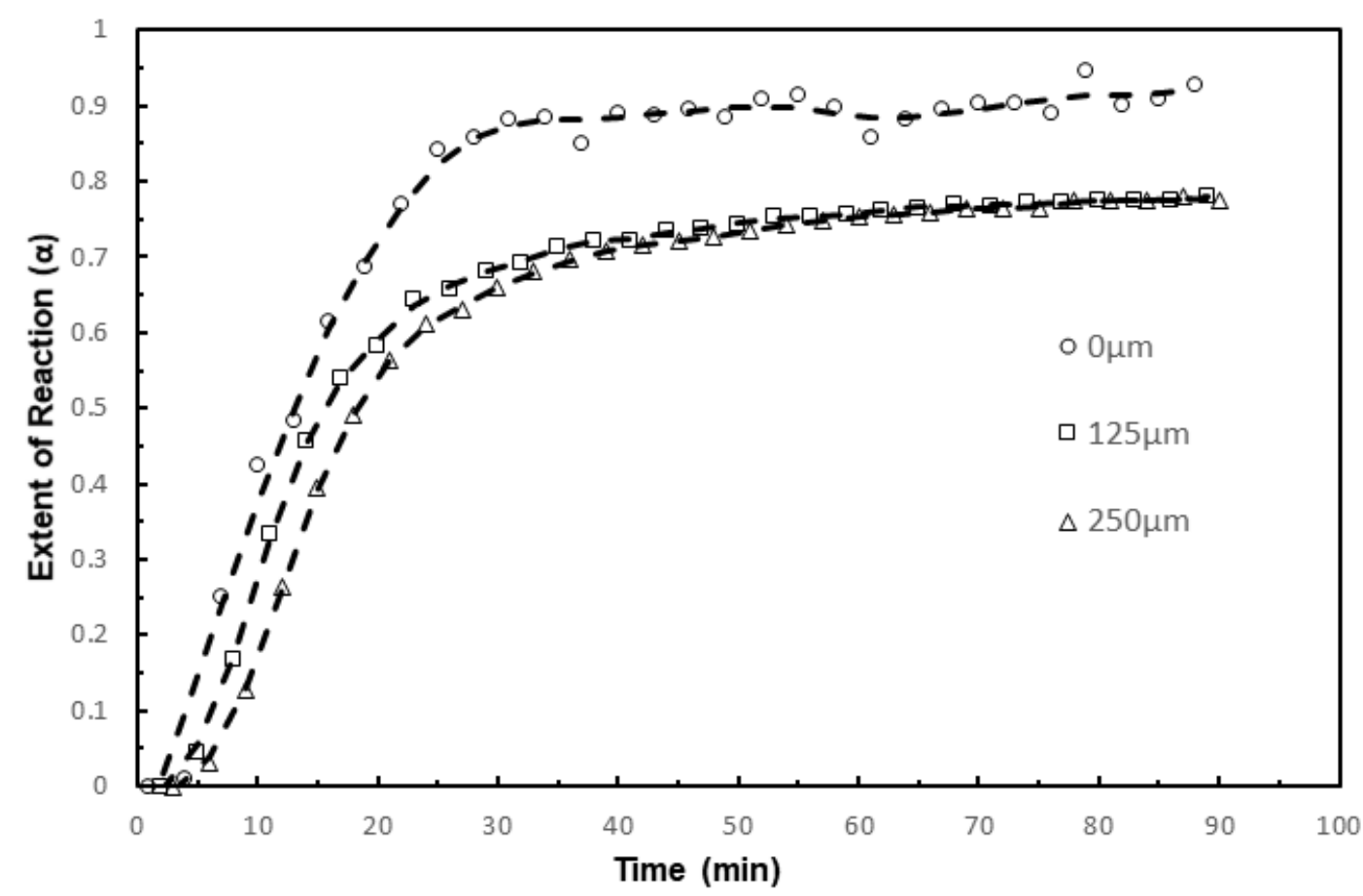

Figure 4: Plot of extent of polymerisation as a function of time at the indicated distances away from the upper ECA/glass interface during polymerisation of Distilled ECA monomer between two glass microscope cover slips that were separated with a $500 \mu \mathrm{m}$ spacer.

Table 2: Kinetic Parameters resulting from the depth profile of Distilled ECA monomer. 


\begin{tabular}{llll}
\hline Depth $/ \mu \mathrm{m}$ & Maximum Rate & $\begin{array}{l}\text { Inhibition time } \\
\boldsymbol{t}_{\text {lag }} / \text { min }\end{array}$ & $\begin{array}{l}\text { Maximum extent of } \\
\text { Reaction }\left[\boldsymbol{\alpha}_{\boldsymbol{t}}\right]_{\boldsymbol{m a x}} / \%\end{array}$ \\
\hline 0 & 0.053 & 1.00 & 94.5 \\
125 & 0.055 & 3.78 & 78.1 \\
250 & 0.047 & 5.47 & 77.9 \\
\hline
\end{tabular}

\section{A study of the Effect of Different Surfaces}

In this investigation the effect of different surfaces on the polymerisation behaviour was determined. The polymerisation was monitored close to the bottom surface at $z \approx 0$. The results shown in Figure 5 and Table 3 demonstrate that changing the substrate surface had a considerable effect on the curing kinetics as expected. However, the slowing of cure at an $\alpha$ value of $\sim 0.8$ could be primarily caused by polymer formation, particularly in the region of the substrate surface, that results in phase separation or vitrification which hinders diffusion of reacting species within the bondline. Exhaustion of bondline initiating species may be of less importance. Gel permeation chromatography analysis of bondline polymer that was obtained from nominally zero gap carbon fibre reinforced epoxy lap shear bonds, which were bonded with a comparatively high stabilising acid content elastomer toughened ECA formulation, has shown that relatively rapid initial cure was followed by much slower cure at high monomer conversion ${ }^{39}$. The slower cure continued at a progressively diminishing rate for many months after bond assembly.

A notable feature of the results outlined in Figure 5 is the substrate dependence of the inhibition times between the surfaces. The basic features of a metal oxide surface are well known, and it provides a useful model in explaining differences between the surfaces tested. At ambient temperatures the outermost surface oxygen's hydrate to form a high density of hydroxyl groups ${ }^{40}$. The variation in stoichiometric hydroxyl content between all surface interfaces along with the acidbase interactions on the oxide layer could provide an explanation for the variation in rate of acid consumption. Notably from Figure 6, copper surfaces exhibited short inhibition times. There is a greater oxide layer thickness (10-50 nm) on a copper surface compared to other metals such as aluminium and mild steel(1-10nm $)^{41,42}$. The basic nature of copper oxide $\mathrm{CuO}$ also contributes to the short inhibition time. For example Glass silicates have similar chemisorbed water molecules that lead to the formation of weakly acidic silanols $\mathrm{Si}-\mathrm{OH}$. Longer inhibition times were recorded on a glass surface compared the more basic copper hydroxide ${ }^{43}$. The presence of alloying metals in Al 2024 shortened the inhibition time of this substrate compared to the pure Al clad counterpart. The trend of higher basicity for $\mathrm{MgO}$ and transition metal oxides has been noted by Smith ${ }^{44}$. A grit blasted Aluminium surface dramatically increased the rate of polymerisation initiation as a decrease in the inhibition time was recorded compared to the smoother aluminium counterpart ${ }^{45}$. The grit blasted surface increased the surface area of the substrate which may have increased the possibility of contact with initiating nucleophilic species on the aluminium surface. The chemistry of substrate surfaces ultimately depends on the chemical or mechanical processing prior to testing. The results also suggest that the surface concentration of hydroxyl groups and the surface geometry are important factors that affect the reactivity of the surface towards initiation of ECA polymerisation. Factors other than substrate basicity such as nucleophilicity and the availability of surface water and 
salts may also be important. In contrast to the other substrates, zero gap glass bonds fixtured almost instantaneously. This may indicate that during gap curing a thin poly CA layer rapidly forms at the glass surface that hinders subsequent interaction of the glass substrate in the curing process. The Raman spectra were affected by the contribution of a significant bond depth above the substrate surface owing to the depth resolution $(\sim 3 \mu \mathrm{m})$ of the measurements. It is therefore possible that even in the absence of an interfacial polymer layer at the glass surface there was, compared to the metal substrates, a limited supply of acid consuming and CA soluble species that diminished glass depth curing. These considerations are investigated in a subsequent paper.

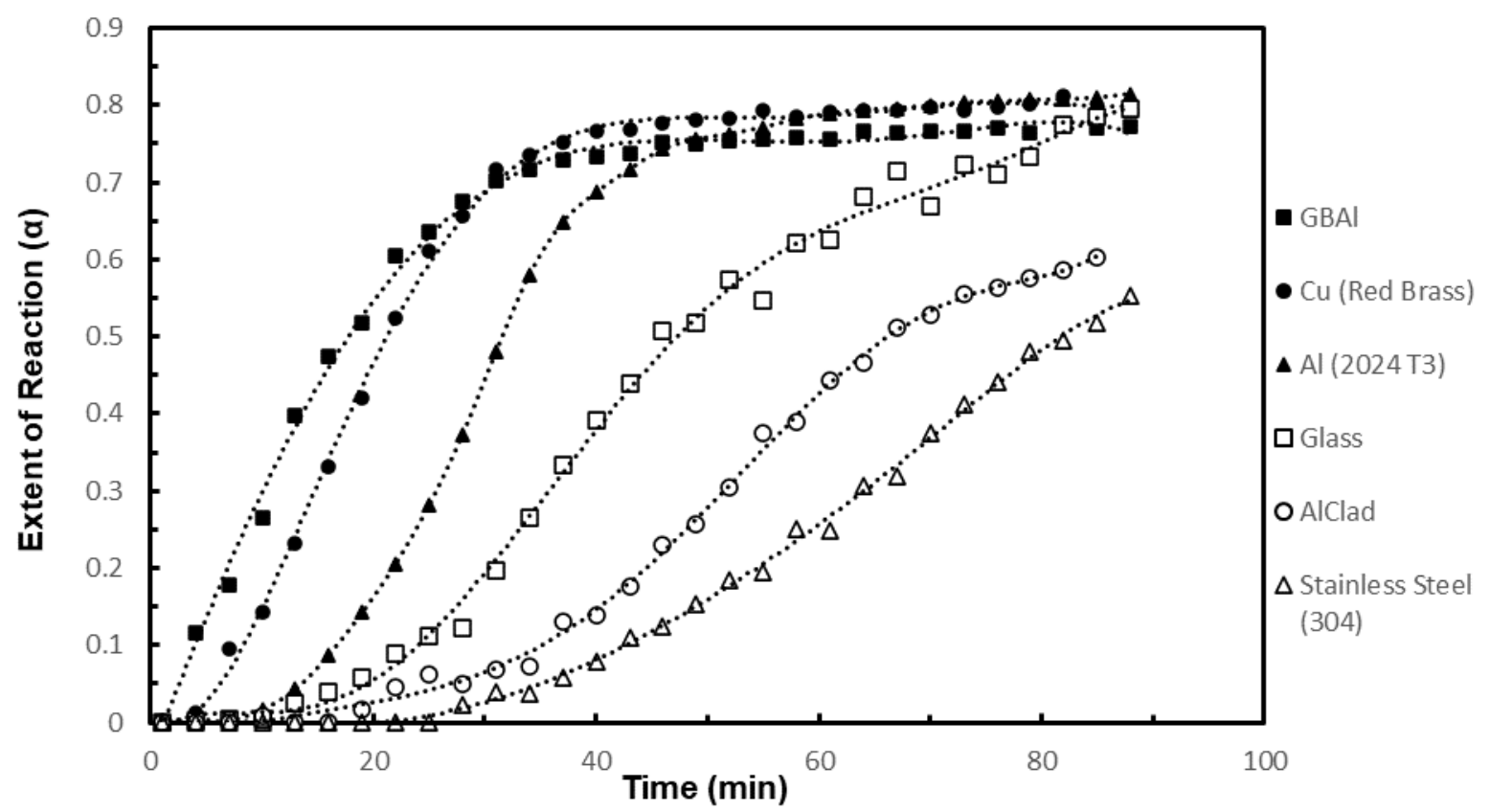

Figure 5: Plots showing the effect of different substrates (Copper (Red Brass), Aluminium Alloy, Grit Blasted Aluminium, Aluminium Clad, Borosilicate Glass, Stainless Steel) on the rate of polymerisation at the ECA/surface interface using a strong acid stabilised model ECA formulation that contained $0.02 \%$ 18-Crown-6. 


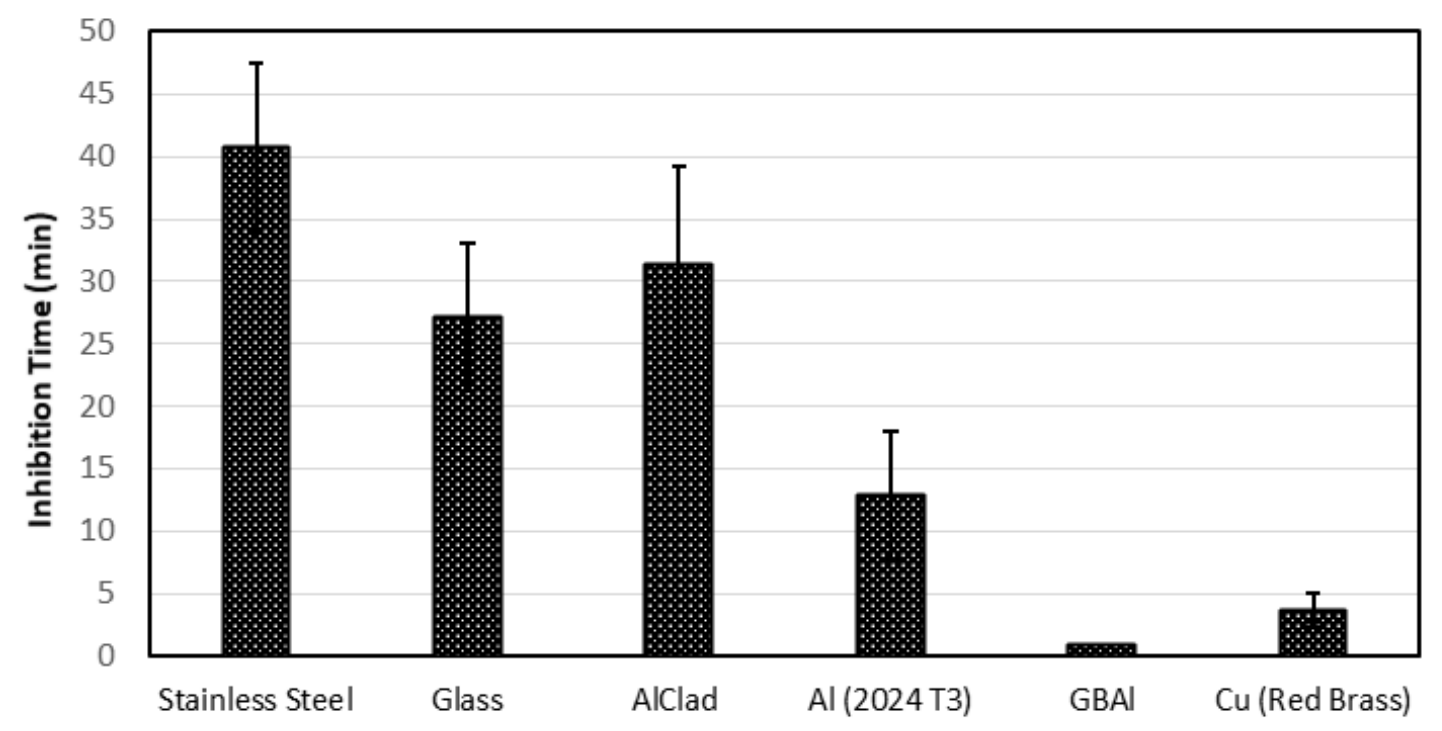

Figure 6: Histogram of the polymerisation inhibition times of the plots shown in Figure 5.

Table 3: Kinetic Parameters obtained from ECA polymerisation on different surfaces shown in Figure 5

\begin{tabular}{llll}
\hline Surface & $\begin{array}{l}\text { Maximum Rate } \\
\boldsymbol{R}_{\boldsymbol{m a x}} / \mathbf{m i n}^{-1}\end{array}$ & $\begin{array}{c}\text { Inhibition time } \\
\boldsymbol{t}_{\boldsymbol{l a g}} / \mathbf{m i n}\end{array}$ & $\begin{array}{l}\text { Maximum extent of } \\
\text { Reaction }\left[\boldsymbol{\alpha}_{\boldsymbol{t}}\right]_{\boldsymbol{m a x}} / \boldsymbol{\%}\end{array}$ \\
\hline Stainless Steel (304) & 0.015 & 40.7 & 55.9 \\
Aluminium Clad & 0.018 & 31.42 & 57.2 \\
Borosilicate Glass & 0.028 & 22.4 & 80.9 \\
Aluminium (2024 T3) & 0.034 & 13.3 & 80.7 \\
Grit Blasted Aluminium & 0.038 & 1.00 & 79.3 \\
(2024 T3) & & & 81.1
\end{tabular}




\section{Effect of Temperature}

From the values outlined in Table 4 the Inhibition times, at least initially, decrease with increasing reaction temperature. The constant measured inhibition times at 35,45 and $55^{\circ} \mathrm{C}$ is a result of the low time resolution of the measurement method. As expected, an increase in temperature caused an increase in the reaction rate as shown in Figure 7. Results were obtained using three separate measurements at each temperature. A linear dependence of the rate of reaction ( $\ln R_{\max }$ ) vs temperature (1/T) was recorded within the range of 291-328 $\mathrm{K}$ as highlighted in Figure 8. Although the Arrhenius plot fit is reasonable, it could also be possible that there are in fact two distinct slopes. For organic reactions this is often considered indicative of a change in mechanism. In this case there appears to be a transition at about $35^{\circ} \mathrm{C}$. Such non-Arrhenius behavior is well-known in enzymatic reactions. For example Roy et al attributed the presence of two slopes to the change in entropic contribution of the environment in their simulation of the catalytic reaction of alcohol dehydrogenase ${ }^{46}$. In this work at the elevated temperatures $\left(>35^{\circ} \mathrm{C}\right)$ the extent of reaction is less sigmoidal in shape which possibly suggest a temperature dependent phase transition into monomer rich and poor phases at a relatively early stage of the reaction. Large differences in activation parameters at a critical temperature due to protein aggregation has been recorded by Biosca et al ${ }^{47}$. Using dielectric spectroscopy Radhakrishnan and Saini reported that in addition to the fast anionic polymerization process, there is likely another process that becomes more significant at longer time scales; the occurrence of secondary bond formation through the nitrile group ${ }^{48}$. This process also becomes more significant at higher temperatures and two activation energies were measured (38.6 $\mathrm{kJmol}^{-1}$ and $16.4 \mathrm{kJmol}^{-1}$ ) which indicates that different mechanistic pathways could be involved in the Arrhenius behavior. It is important to also remember that the in-situ measurements taken here refer to reactions at the ECA/aluminium surface interface which are affected by factors not typically observed in homogenous solution phase reactions. As noted in the previous section, the overall polymerisation rate that was recorded on a surface was determined by the surface chemistry, consumption of reactant species and diffusion rates. The overall reaction rate $R_{\max }$ encompasses more than a single reaction but is the sum of complex multi-step reactions with associated energy barriers. Visual inspection of the shape of the isothermal reaction curves provides clear evidence of multiple reactions as both sigmoidal and decelerating reaction processes were recorded. Vyazovkin et $\mathrm{a}^{49}$ and Galwey \&Brown ${ }^{50}$ reported the limitations of the use of Arrhenius theory in such solid state reactions. These aspects of bulk polymerisations restrict the use of the Arrhenius expression shown in equation 6 . From the observed rate only an approximate or effective Activation energy $E_{e f}$ can be calculated ${ }^{51}$.

$$
k=A e^{-E_{a} / R T}
$$

Where, $k, E_{a}, R, \mathrm{~T}$, are the rate constant, activation energy, gas constant and absolute temperature respectively.

Non-linear regression models describing the unique overlapping reactions of the system may be required in order to determine the kinetic parameters of individual reaction steps. Knowledge of the concentration of reacting species is also necessary. This investigation primarily emphasises the utility 
of CRM to follow the interfacial rate of extremely reactive anionic polymerisation of cyanoacrylate systems over a range of temperatures. A similar investigation conducted over a larger number of temperatures would be useful to verify this transition from one apparent Arrhenius plot section to another.

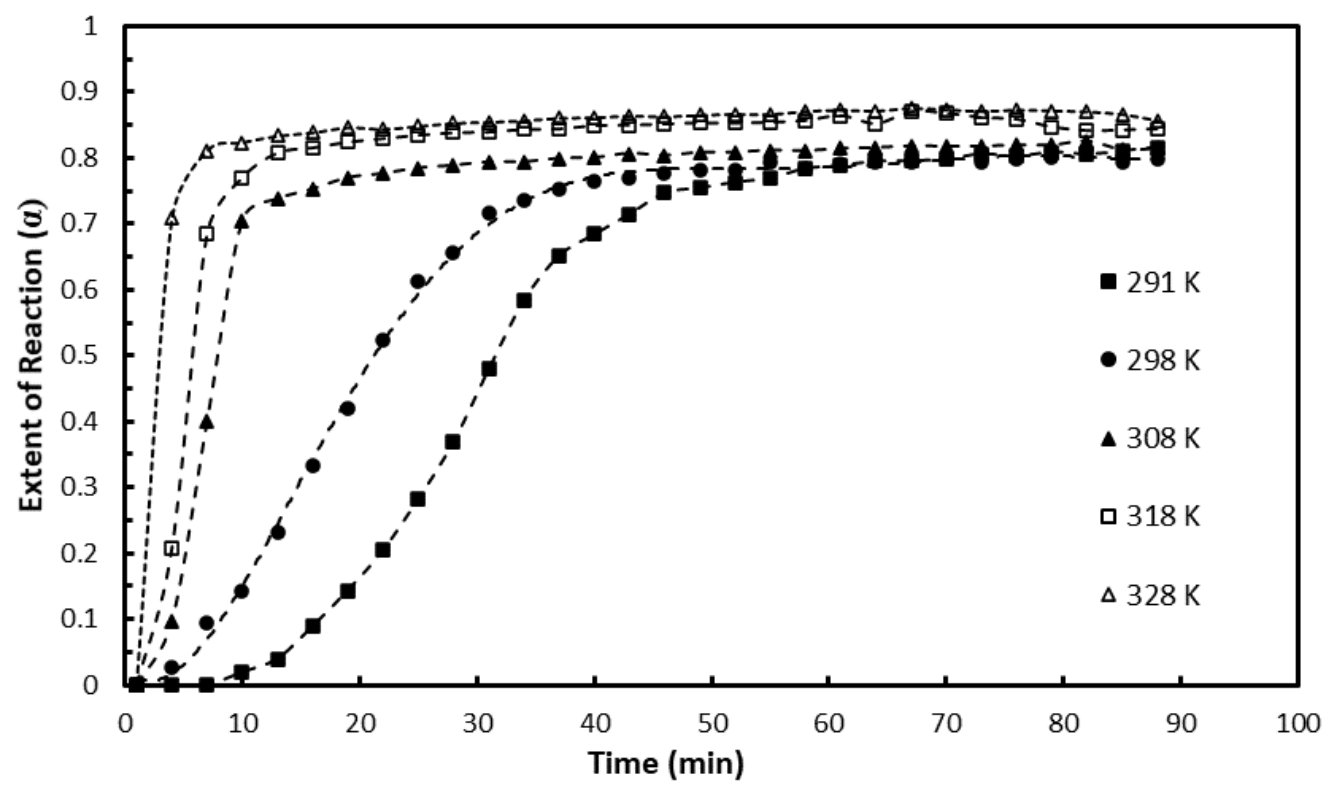

Figure 7: Relative monomer content as function of time and temperature during polymerisation on an aluminium (2024 T3) surface. Results displayed are the average of three separate measurements conducted at each temperature.

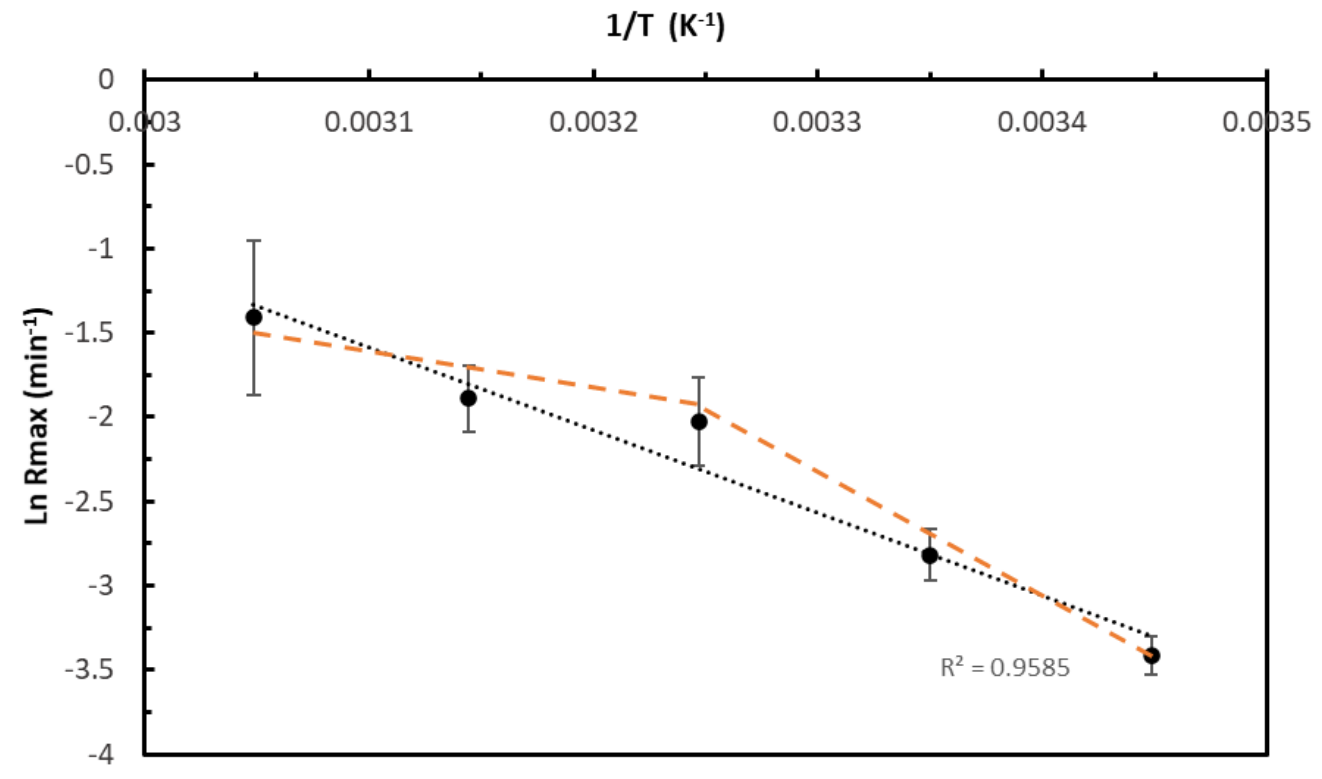


Figure 8: The dependence of the maximum rate $\ln \left(R_{\max }\right)$ on reciprocal temperature for the anionic polymerisation of ethyl CA at $z \approx 0$ on an aluminium (2024 T3) surface within the temperature range of 291-328 K.

Table 4: Kinetic Parameters resulting from the effect of different temperatures on ECA polymerisation on Aluminium 2024 Surface.

\begin{tabular}{llll}
\hline $\begin{array}{l}\text { Surface Temperature } \\
\mathrm{K}\end{array}$ & $\begin{array}{l}\text { Maximum Rate } \\
R_{\max } / \mathrm{min}^{-1}\end{array}$ & $\begin{array}{l}\text { Inhibition time } \\
\mathrm{t}_{\text {lag }} / \mathrm{min}\end{array}$ & $\begin{array}{l}\text { Maximum extent of } \\
\text { Reaction }[\alpha] t_{\max } / \%\end{array}$ \\
\hline 291 & 0.033 & 12.96 & 81.5 \\
298 & 0.059 & 3.45 & 79.9 \\
308 & 0.132 & 1.0 & 81.6 \\
318 & 0.146 & 1.0 & 84.3 \\
328 & 0.244 & 1.0 & 85.7
\end{tabular}

\section{Conclusions}

The intention of this research was to characterise the cure depth profile of a surface-initiated cyanoacrylate adhesive. Confocal Raman Spectroscopy combined with piecewise regression analysis is uniquely suitable for characterising the heterogeneous curing behaviour of Cyanoacrylate in an adhesive bondline. In-situ monitoring of the double bond decay at various spatial regions within adhesive bonds has shown that there were significant regional differences in the curing rates and extent of reaction. By following the spectral changes during curing a detailed picture of the curing process was obtained. Furthermore, the effect of temperature and surface type were determined. Using the method developed, pronounced effects of the surface material on the rate of ECA polymerisation reaction were noted. The gap curing activity (rate) of the substrate surfaces was ordered as follows, GBAl > Cu (Red Brass) > Al (2024) > Glass > Al > SS (304). There are many variables that can influence the final polymer network; thus, it is essential to isolate each parameter and to examine them independently. In the future, this work will be extended to various other formulations in order to gain a better understanding of the curing process with the intention of optimising bonding performance.

\section{Acknowledgement}

The FOCAS Institute is funded under the National Development Plan 2000-2006 with assistance from the European Regional Development Fund. The authors gratefully acknowledge the award of a TU Dublin-Henkel Enterprise Scholarship for the support and supply of many materials. 


\section{References}

1. Pepper DC, Ryan B. Initiation Processes in Polymerizations of Alkyl Cyanoacrylates by Tertiary Amines: Inhibition by Strong Acids. Makromol Chemie. 1983; 184:383-394.

2. Pepper DC, Ryan B. Kinetics of Polymerization of Alkyl Cyanoacrylates by Tertiary Amines and Phosphines. Makromolecular Chem. 1983; 184:395-410.

3. Pepper DC. Anionic and Zwitterionic Polymerization of $\alpha$-Cyanoacrylates. J Plymer Sci Polym. 1978; 62:65-77.

4. Nedvedova M, Kresalek V, Vaskova H, Provaznik I. Studying the Kinetics of n-ButylCyanoacrylate Tissue Adhesive and Its Oily Mixtures. J Infrared, Millimeter, Terahertz Waves. 2016; 37(10):1043-1054.

5. Tomlinson SK, Ghita OR, Hooper RM, Evans KE. The use of near-infrared spectroscopy for the cure monitoring of an ethyl cyanoacrylate adhesive. Vib Spectrosc. 2006; 40(1):133-141.

6. Estan-Cerezo G, Alonso DA, Martín-Martínez JM. Structural and adhesion properties of poly(ethyl 2-cyanoacrylate) post-cured at different temperatures and times. J Adhes Sci Technol. 2019; 33(4):329-345.

7. Everall NJ. Confocal Raman microscopy: common errors and artefacts. Analyst. 2010; 135(10):2512-2522.

8. Everall NJ. Confocal Raman microscopy: Why the depth resolution and spatial accuracy can be much worse than you think. Appl Spectrosc. 2000; 54(10):1515-1520.

9. Tfayli A, Piot O, Manfait M. Confocal Raman microspectroscopy on excised human skin: uncertainties in depth profiling and mathematical correction applied to dermatological drug permeation. J Biophotonics. 2008; 1(2):140-153.

10. Tomba JP, Pastor JM. Confocal Raman microspectroscopy with dry objectives: A depth profiling study on polymer films. Vib Spectrosc. 2007; 44(1):62-68.

11. Freebody NA, Vaughan AS, Macdonald AM. On optical depth profiling using confocal Raman spectroscopy. Anal Bioanal Chem. 2010; 396(8):2813-2823.

12. Schrof W, Beck E, Etzrodt G, Hintze-Brüning H, Meisenburg U, Schwalm R, et al. Depthresolved characterization of UV cured coatings by confocal Raman and two-photon microscopy. Prog Org Coatings. 2001; 43(1-3):1-9.

13. Schrof W, Beck E, Königer R, Reich W, Schwalm R. Depth profiling of UV cured coatings containing photostabilizers by confocal Raman microscopy. Prog Org Coatings. 1999; 35(14):197-204.

14. Belaroui F, Grohens Y, Boyer H, Holl Y. Depth profiling of small molecules in dry latex films by confocal Raman spectroscopy. Polymer. 2000; 41(21):7641-7645.

15. Courtecuisse F, Cerezo J, Croutxé-Barghorn C, Dietlin C, Allonas X. Depth characterization by confocal raman microscopy of oxygen inhibition in free radical photopolymerization of acrylates: Contribution of the thiol chemistry. J Polym Sci Part A Polym Chem. 2013; 51(3):635-643.

16. Smith-Palmer T, Lin S, Oguejiofor I. In Situ Confocal Raman Microscopy of Hydrated Early Stages of Bacterial Biofilm Formation on Various Surfaces in a Flow Cell. Appl Spectrosc. 2016; 
70(2):289-301.

17. Edwards HGM, Day JS. Fourier transform Raman spectroscopic studies of the curing of cyanoacrylate glue. J Raman Spectrosc. 2004; 35(7):555-560.

18. Day JS, Edwards HGM, Dobrowski S a, Voice AM. The detection of drugs of abuse in fingerprints using Raman spectroscopy II: cyanoacrylate-fumed fingerprints. Spectrochim Acta A Mol Biomol Spectrosc. 2004; 60(8-9):1725-1730.

19. Li YJ, Barthès-Biesel $D$, Salsac A V. Polymerization kinetics of n-butyl cyanoacrylate glues used for vascular embolization. J Mech Behav Biomed Mater. 2017; 69:307-317.

20. Miguel MDLP, Pablo Tomba J. A comparison of different approaches for depth profiling of films and coatings by confocal Raman microscopy. Prog Org Coatings. 2012; 74(1):43-49.

21. Henkel. Design Guide for Bonding Metals. Vol. 6, Technical Brochure. 2014.

22. Liland KH. 4S Peak Filling - baseline estimation by iterative mean suppression. MethodsX. 2015; 2(March):135-140.

23. Savitzky A, Golay MJE. Smoothing and differentiation of data by simplified least-squares procedures. Anal Chem. 1964; 36(8):1627-1639.

24. Rocks J, Rintoul L, Vohwinkel F, George G. The kinetics and mechanism of cure of an aminoglycidyl epoxy resin by a co-anhydride as studied by FT-Raman spectroscopy. Polymer. 2004; 45(20):6799-6811.

25. Edwards HGM, Johal KS, Johnson AF. FT-Raman spectroscopic monitoring of the grouptransfer polymerisation of methyl methacrylate. Vib Spectrosc. 2006; 41(2):160-169.

26. G.Costa, J.P.Cronin, Pepper D. Termination and Transfer by acids in the Pyridine-Initiatied Polymerisation of Butyl Cyanoacrylate. Eur Polym J. 1983; 19(10):939-945.

27. Schmitt M, Schulze-Pillot R, Hempelmann R. Kinetics of bulk polymerisation and Gompertz's law. Phys Chem Chem Phys. 2011; 13(5):690-695.

28. Watzky MA, Finke RG. Transition metal nanocluster formation kinetic and mechanistic studies. A new mechanism when hydrogen is the reductant: Slow, continuous nucleation and fast autocatalytic surface growth. J Am Chem Soc. 1997; 119(43):10382-10400.

29. Uversky VN, Li J, Fink AL. Evidence for a Partially Folded Intermediate in $\alpha$-Synuclein Fibril Formation. J Biol Chem. 2001; 276(14):10737-10744.

30. Swinnen IAM, Bernaerts K, Dens EJJ, Geeraerd AH, Van Impe JF. Predictive modelling of the microbial lag phase: A review. Int J Food Microbiol. 2004; 94(2):137-159.

31. Jašo $V$, Stoiljković $D$, Radičević $R$, Bera $O$. Kinetic modeling of bulk free-radical polymerization of methyl methacrylate. Polym J. 2013; 45(6):631-636.

32. Pollock DSG. Smoothing with Cubic Splines. In: Handbook of Time Series Analysis, Signal Processing, and Dynamics. London: Academic Press; 1999. p. 293-322.

33. Muggeo VM. Segmented: An R package to Fit Regression Models with Broken-Line Relationships. R News. 2008; 8(1):20-25.

34. Jauk E, Benedek M, Dunst B, Neubauer AC. The relationship between intelligence and creativity: New support for the threshold hypothesis by means of empirical breakpoint detection. Intelligence. 2013; 41(4):212-221. 
35. Campra P, Morales M, Es P. Trend analysis by a piecewise linear regression model applied to surface air temperatures in Southeastern Spain. Nonlin Process Geophys Discuss Nonlin Process Geophys Discuss. 2016; 5194(10):2016-2029.

36. Bacher R, Leng N, Chu L-F, Thomson J, Kendziorski C, Stewart R. Trendy: Segmented regression analysis of expression dynamics for high-throughput ordered profiling experiments. BMC Bioinformatics. 2017; 380(19):1-10.

37. Malash GF, El-Khaiary MI. Piecewise linear regression: A statistical method for the analysis of experimental adsorption data by the intraparticle-diffusion models. Chem Eng J. 2010; 163(3):256-263.

38. Siebel D, Scharfer P, Schabel W. Determination of Concentration-Dependent Diffusion Coefficients in Polymer-Solvent Systems: Analysis of Concentration Profiles Measured by Raman Spectroscopy during Single Drying Experiments Excluding Boundary Conditions and Phase Equilibrium. Macromolecules. 2015; 48(23):8608-8614.

39. Stefanov T, Ryan B, Ivanković A, Murphy N. Mechanical bulk properties and fracture toughness of composite-to-composite joints of an elastomer-toughened ethyl cyanoacrylate adhesive. Int J Adhes Adhes. 2016; 68:142-155.

40. Cabrera-Sierra R, Pech-Canul MA, González I. The Role of Hydroxide in the Electrochemical Impedance Response of Passive Films in Corrosion Environments. J Electrochem Soc. 2006; 153(3):101-107.

41. Keil P, Lützenkirchen-Hecht D, Frahm R. Investigation of room temperature oxidation of $\mathrm{Cu}$ in air by Yoneda-XAFS. AIP Conf Proc. 2007; 882:490-502.

42. Alexander MR, Thompson GE, Zhou X, Beamson G, Fairley N. Quantification of oxide film thickness at the surface of aluminium using XPS. Surf Interface Anal. 2002; 34(1):485-489.

43. A. Auroux, Gervasini A. Microcalorimetric Study of the Acidity and Basicity of Metal Oxide Surfaces. J Phys Chem. 1990; 94(16):6371-6379.

44. Smith DW. An acidity scale for binary oxides. J Chem Educ. 1987; 64(6):480-481.

45. Fowkes FM, Dwight DW, Cole DA, Huang TC. Acid-base properties of glass surfaces. J Non Cryst Solids. 1990 Apr; 120(1-3):47-60.

46. Roy S, Schopf $P$, Warshel A. Origin of the Non-Arrhenius Behavior of the Rates of Enzymatic Reactions. J Phys Chem B. 2017; 121(27):6520-6526.

47. Biosca JA, Travers F, Barman TE. A jump in an Arrhenius plot can be the consequence of a phase transition. The binding of ATP to myosin subfragment 1. FEBS Lett. 1983; 153(1):217220.

48. Radhakrishnan S, Saini DR. Dielectric Monitoring. Polym Eng Sci. 1993; 33(3):125-131.

49. Vyazovkin S, Burnham AK, Criado JM, Pérez-Maqueda LA, Popescu C, Sbirrazzuoli N. ICTAC Kinetics Committee recommendations for performing kinetic computations on thermal analysis data. Thermochim Acta. 2011; 520(1-2):1-19.

50. Galwey AK, Brown ME. Application of the arrhenius equation to solid state kinetics: Can this be justified? Thermochim Acta. 2002; 386(1):91-98.

51. Vyazovkin S. On the phenomenon of variable activation energy for condensed phase reactions. New J Chem. 2000; 24(11):913-917. 
